\title{
Interpretação dos grupos adimensionais que regem a taxa de transferência de calor de uma célula de combustão
}

\author{
Pretti, J. N. ${ }^{1}$; Martins, M.F. ${ }^{1}$ \\ 1 Programa de Pós-Graduação em Engenharia Mecânica, Universidade Federal do Espírito Santo, Vitória, ES, Brasil
}

\begin{abstract}
Resumo
Com o constante aumento da demanda energética industrial e populacional é necessário o estudo de fontes alternativas de energia, bem como técnicas para sua conversão em trabalho útil, em diferentes escalas de consumo. Outro fator importante é que a humanidade está produzindo cada vez mais resíduos sólidos, e nestes, existe um potencial energético que não pode ser negligenciado. Neste contexto, a combustão se mostra uma boa alternativa para o reaproveitamento energético desses resíduos, no entanto, é indispensável um entendimento do processo, bem como das variáveis de operação. Portanto, este trabalho tem como objetivo apresentar a equação que governa a transferência de calor em um meio poroso reativo da fase sólida e, ao mesmo tempo, realizar uma análise adimensional do fenômeno pela determinação e interpretação física dos grupos adimensionais que regem a taxa de transferência de calor da fase sólida de uma célula de combustão desenvolvida no Laboratório de Combustíveis e Combustão da Universidade Federal do Espírito Santo para estudos da combustão em meio poroso.
\end{abstract}

Palavras chaves: resíduos sólidos, célula de combustão, grupos adimensionais.

\section{Introdução}

A Universidade Federal do Espírito Santo deu início aos estudos da tecnologia de combustão de resíduos sólidos ao conceber uma célula de combustão instrumentada objetivando desenvolver pesquisas neste âmbito, Monhol e Pretti (2013).

Nesta conjuntura, o presente trabalho se propõe a apresentar a equação que governa a transferência de calor em um meio poroso reativo para a fase sólida e, ao mesmo tempo, determinar parâmetros adimensionais ou grupos adimensionais que regem este fenômeno.

\section{Metodologia}

\subsection{Apresentação do problema}

Resumidamente, para descrever a equação unidimensional da transferência de calor no meio poroso reativo para a fase sólida, tem-se:

$$
\begin{gathered}
\varepsilon_{s \cdot}\left(\rho c_{P}\right)_{s} \frac{\partial T_{s}}{\partial t} \\
=\frac{\partial}{\partial x}\left(\lambda_{s} \frac{\partial T_{s}}{\partial x}\right)+\Gamma_{g, s} \cdot\left(T_{s}-T_{g}\right)+Q_{g} h\left(T_{a m b}-T_{s}\right)
\end{gathered}
$$

Pode-se notar que o modelo de equações diferenciais parciais requer um método numérico para sua solução, uma vez que não é possível encontrar solução analítica para o problema. No presente trabalho utilizou-se o modelo discreto por diferenças finitas.

\subsection{Teorema Pi de Buckingham}

De posse da equação (1) apresentada aplicou-se o Teorema Pi de Buckingham para determinar os grupos adimensionais que regem a equação de energia para a fase sólida. Logo esta equação pode ser descrita pelos grupos adimensionais conforme abaixo:

$$
\begin{gathered}
\Theta=\frac{T_{s}-T_{g}}{T_{f s}-T_{g}} \\
=f\left(\frac{x}{L}, \frac{Q_{g} \cdot L^{2}}{\lambda_{s}\left(T_{f s}-T_{g}\right)}, \frac{L^{2} \cdot \Gamma_{g, s}}{\lambda_{s}}, \frac{h \cdot L}{\lambda_{s}}, \frac{\lambda_{s} \cdot t}{L^{2} \cdot\left(\rho c_{P}\right)_{s}}\right)
\end{gathered}
$$

\section{Resultados e Discussões}

Para fazer uma interpretação física dos grupos adimensionais envolvidos no problema optou-se por resolver a equação diferencial para o balanço de energia da fase sólida numericamente fazendo uso do método das diferenças finitas. 
De posse de uma solução numérica pode-se plotar gráficos relacionando a temperatura adimensional com quaisquer um dos outros grupos adimensionais obtidos.

A Figura 1 apresenta uma interpretação física para três grupos adimensionais do problema em questão em relação à temperatura adimensional.
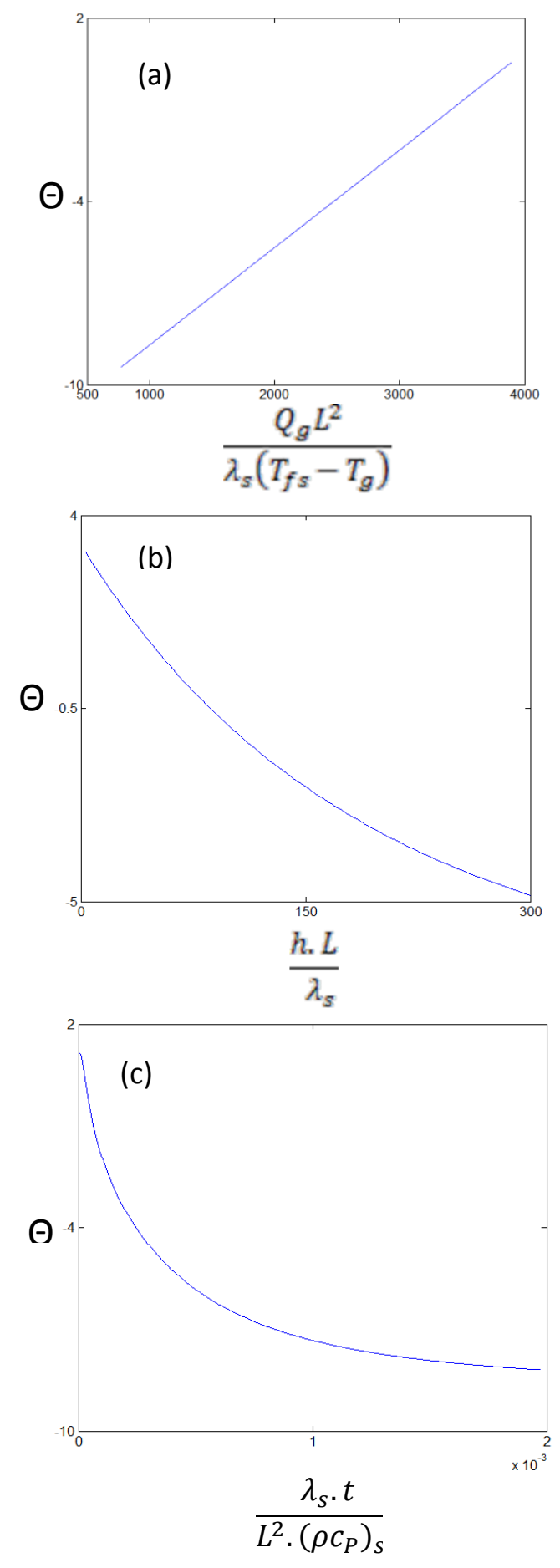

Figura 1: Interpretação física de grupos adimensionais.

Conforme pode-se observar nos gráficos $a, b$ e $c$ ilustrados na Figura (1) a relação funcional da temperatura adimensional com os demais grupos adimensionais apresenta comportamentos distintos.
Para obtenção do gráfico "a" variou-se a taxa de geração de calor no interior do leito, em uma posição qualquer, e plotou-se a correspondente temperatura adimensional. Percebe-se que a relação entre estes grupos adimensionais é aproximadamente linear.

No gráfico "b", variou-se positivamente o coeficiente de troca térmica convectiva e notou-se um decaimento da temperatura adimensional, como esperado. Por último, no gráfico "c", variou-se positivamente a condutividade térmica do sólido e notou-se um rápido decaimento da temperatura adimensional, uma vez que aumentou-se a dissipação de calor no interior do leito.

Em suma, percebe-se que a análise prévia da relação entre os grupos adimensionais envolvidos em um dado problema como este é de grande valia, uma vez que pode-se obter predições da influencia de cada grupo $\mathrm{Pi}$ na temperatura adimensional.

\section{Considerações Finais}

Através deste artigo pode-se notar que o uso do método da análise adimensional nos permite adquirir conhecimento de um dado fenômeno antes que seja feito extensas análises teóricas ou experimentais, permitindo extrair tendências de dados que de outra forma ficariam desorganizados e incoerentes.

\section{Agradecimentos}

Os autores agradecem a CAPES pelo apoio financeiro, ao programa de pós-graduação em engenharia mecânica e ao Laboratório de Combustíveis e Combustão da UFES.

\section{Referências}

\section{Artigos}

[1] MONHOL F. A.; PRETTI J. N.; MARTINS M. F., Concepção e calibração de uma célula de combustão minuciosamente instrumentada para conversão de resíduos sólidos como fonte alternativa de energia, 2013.

[2] LAPENE, A.; M. F. MARTINS; G. DEBENEST; M. QUINTARD; S. SALVADOR, "Numerical simulation of oil shale combustion in a fixed bed: modelling and chemical." Eurotherm Seminar $N^{\circ} 81$ Reactive Heat Transfer in Porous Media. Albi, France, 2007.

\section{Livros}

[3] ROBERT W. FOX, PHILIPJ. PRITCHARD, ALAN T. MCDONALD, "Introdução à Mecânica dos Fluidos", $7^{\text {a }}$ edição, capítulo 7, 2008. 